BULLETIN Bulletin hispanique

HISPANIQUE Université Michel de Montaigne Bordeaux

119-1 | 2017

Autorité et pouvoir dans le théâtre du Siècle d'Or

\title{
Un hito previo al estudio del género sacramental en la posguerra española
}

Los autos de Lope de Vega en la conmemoración de su tricentenario

Juan Manuel Escudero Baztán

\section{(2) OpenEdition}

\section{Journals}

Edición electrónica

URL: http://journals.openedition.org/bulletinhispanique/4807

DOI: 10.4000/bulletinhispanique.4807

ISBN: 979-10-300-0142-6

ISSN: $1775-3821$

\section{Editor}

Presses universitaires de Bordeaux

\section{Edición impresa}

Fecha de publicación: 15 junio 2017

Paginación: 133-142

ISBN: 979-10-300-0141-9

ISSN: 0007-4640

\section{Referencia electrónica}

Juan Manuel Escudero Baztán, « Un hito previo al estudio del género sacramental en la posguerra española », Bulletin hispanique [En línea], 119-1 | 2017, Publicado el 15 junio 2020, consultado el 15 septiembre 2020. URL : http://journals.openedition.org/bulletinhispanique/4807 ; DOI : https://doi.org/ 10.4000/bulletinhispanique.4807 


\title{
Un hito previo al estudio del género sacramental en la posguerra española: Los autos de Lope de Vega en la conmemoración de su tricentenario ${ }^{1}$
}

\author{
Juan Manuel Escudero Baztán \\ GRISO-Universidad de Navarra
}

Cet article examine les célébrations organisées en 1935 à l'occasion du tricentenaire de la mort de Lope de Vega autour de ses autos sacramentales à travers une revue : Cruz y Raya et l'apparition dans la presse de Madrid (le journal Ya) de quatre articles du directeur théâtral Felipe Lluch.

Mots-clés: Lope de Vega, tricentenaire, autos sacramentales, Felipe Lluch.

Este trabajo repasa los actos celebrativos de 1935 con motivo del tercer centenario de la muerte de Lope de Vega con respecto a sus autos sacramentales, a través de una publicación periódica Cruz y Raya y la aparición en el periódico madrileńo Ya de cuatro artículos del director teatral Felipe Lluch.

Palabras clave: Lope de Vega, tricentenario, autos sacramentales, Felipe Lluch.

This paper reviews the 1935 celebratory events marking the tercentenary of the death of Lope de Vega, with respect to its sacramental plays through a journal Cruz $y$ Raya and the appearance in the Madrid press (The $Y a$ newspaper) of four articles written by Felipe Lluch (theatre director).

Keywords: Lope de Vega, tercentenary, sacramental plays, Felipe Lluch.

1. Este trabajo se enmarca dentro del proyecto de autos sacramentales completos de Lope de Vega. Estudio, edición y contexto histórico, financiado por el Ministerio Economía y Competitividad, Gobierno de España. Dirección General de Investigación y Gestión del Plan Nacional de I+D+I. Subprograma de Proyectos de Investigación de la Excelencia (FFI201345388-P). 
T a producción dramática clásica española tuvo una presencia bastante Lestacada en el teatro español de posguerra. Un buen puñado de títulos fueron llevados a las tablas en su condición de figurantes destacados de una legitimación cultural buscada por el Régimen de Franco. Si a esa postura revisionista, y continuista con los ideales imperiales de la Espańa de los Austrias, se le añade el fuerte sesgo neocatólico de la España franquista en sus primeros ańos tras la Guerra Civil, se entiende que una parte significativa de ese teatro clásico fuera representada por el género sacramental, que parecía, a priori, reunir tanto la idea de continuidad imperial como la idea de la renacida España católica. Sin embargo, esa instrumentalización tenía serios problemas de prosperar al haber perdido el género sacramental su conexión con el público y contar con una estética ultrabarroca que había sufrido el desprestigio de las élites políticas a partir del siglo xviII. En suma, no era el auto sacramental el género más adecuado para reivindicar los valores de la nueva Espańa que nacía tras la contienda. Pero los ideólogos del Régimen no dudaron en usarlo como forma de defender y alentar el fulgurante catolicismo de la nación. Era obvio que lo que le deparaba al auto sacramental en los largos ańos de la posguerra era un uso instrumental de proyección política de la sociedad conservadora espańola y la exaltación casi mística de una nueva sociedad de profundos valores cristianos. Las cualidades artísticas, teatrales quedarían, sin duda, relegadas a un segundo plano. Pero esta situación empujada por la conciencia falangista de creación de un nuevo orden histórico, estético y moral no fue siempre uniforme, ni defendida por todos los representantes de los sectores conservadores de la sociedad española. Tuvo unos precedentes, inmediatamente anteriores a la Guerra Civil, cristalizados en la celebración del Tricentenario de la muerte de Lope de 1935, y en varias iniciativas surgidas dentro de los fastos celebrativos, que, no obstante, fueron mucho más discretos que los que recibiera Calderón en su bicentenario de $1881^{2}$. El acto oficial central del Tricentenario fue el montaje de La dama boba, en versión de García Lorca, en la Chopera del Retiro (27 de agosto de 1935).

De todos estos fastos, bastante irrelevantes, de forma singular cobraron cierto protagonismo los autos sacramentales lopianos tanto en los contenidos de una revista de incipiente nacimiento como Cruz y Raya como en una serie de artículos publicados en la prensa madrileña por Felipe Lluch ${ }^{3}$, sorprendentemente vistos

2. Como analiza con detalle David Rodríguez-Solás, Teatros nacionales republicanos: la Segunda República y el teatro clásico español, Iberoamericana / Vervuert, Madrid / Frankfurt, 2014, p. 170 y ss.

3. Debo la escritura de este escueto trabajo a la generosidad de mi colega Víctor García Ruiz, quien en su día me informó sobre estos artículos publicados en la prensa de Felipe Lluch, en los que trataba las cuestiones que aquí estudio sobre los autos sacramentales de Lope, que habían pasado inadvertidos para la crítica. Mi aportación debe entenderse como un estudio ceńido a un tema muy concreto que García Ruiz menciona de pasada en su trabajo «Beneméritos cruzados de la cultura española: el tricentenario de Lope en el ámbito conservador español», Anuario Lope de Vega, 22, 2016. En la dirección: <http://revistes.uab.cat/anuariolopedevega/article/view/v22garcia-ruiz/ 147-pdf-es>. 
desde una perspectiva más artística que de maniqueísmo político, como una vindicación del Lope popular y una propuesta de modernización de la escena española a través de su representación. En esta ocasión, los comentarios que siguen se centran en la labor de divulgación seguida por Cruz y Raya y los artículos de prensa escritos por Lluch.

Haciendo un rápido resumen, Cruz y Raya: revista de afirmación y negación nacida el 15 de abril de 1933, tuvo desde sus inicios una historia singular cuando un grupo de católicos, que había reunido un millón de pesetas para fundar un colegio donde se enseñara religión de forma no obligatoria, cambió de proyecto y le entregó ese dinero a José Bergamín (1895-1983) para que dirigiera una revista católica. Bergamín, apoyándose en la mentalidad burguesa y liberal de los socios inversores, imprimió a la revista una identidad tan declaradamente católica como firmemente no confesional y clerical ${ }^{4}$. El delicado equilibrio de fuerzas y la contorsión ideológica que aunaba catolicismo y liberalismo se rompió definitivamente cuando estalló la revolución de 1934 y la postura radical de su director más del lado liberal que del confesional acabó con la revista entre la desbandada general. La atención al Tricentenario de Lope por parte de Cruz y Raya se produjo, pues, en una etapa de tensiones internas dentro de la revista. Lo cierto es que el Tricentenario cuadraba perfectamente no solo con el perfil netamente intelectual de la revista, sino con la predilección de Bergamín por el Siglo de Oro español.

Cruz y Raya dedicó íntegro a Lope el número doble 23-24 (febrero-marzo 1935), noventa páginas de estudios, más de cien con la antología poética que se seguía luego, y otras tantas para el auto de La maya, publicado en suplemento, sobre papel de distinto color (verde) y con tirada exenta (habitualmente, entre quinientos y mil ejemplares) para su comercialización en librerías. Se incluía ahí un artículo del propio Bergamín: «Lope, siguiendo el dictamen del aire que lo dibuja», típico de las ideas un tanto atrabiliarias que solía plasmar el autor en sus escritos. Y un trabajo mucho más sólido y académico, de la mano de un prestigioso lopista, José Fernández Montesinos ${ }^{5}$, «Lope, figura del donaire», donde se discutía sobre la pertinencia o no de ciertos elementos autobiográficos de Lope en La Dorotea, complementado por otro artículo de Amado Alonso ${ }^{6}$ quien señalaba «el riesgo de pecado de lesa poesía que hay en el indiscreto aprovechamiento de la biografía de Lope para la interpretación poética de su obra». Cerraban el número, de esmerada impresión, una selección de poemas,

4. Sintetizo aquí lo expuesto en Víctor García Ruiz, Víctor, Teatro y fascismo en España: el itinerario de Felipe Lluch, Iberoamericana / Vervuert, Madrid / Frankfurt, 2010, p. 161-71. Más detalles en Jean Bécarud, Cruz y Raya (1933-1936), Taurus, Madrid, 1969.

5. Ver José Fernández Montesinos, «Algunas observaciones sobre la figura del donaire en el teatro de Lope de Vega», en AA.VV., Homenaje ofrecido a Menéndez Pidal: miscelánea de estudios lingüísticos, literarios e históricos, Madrid, Librería y casa editorial Hernando, 1925, vol. 1, p. 469504. Y después publicado con ligeros cambios en Cruz y Raya (José Fernández Montesinos, «Lope, figura del donaire», Cruz y Raya, 23-24, núm. febrero-marzo, 1935, p. 53-85).

6. Ver Amado Alonso, «Vida y creación en la lírica de Lope», Cruz y Raya, 34, núm. enero, 1936, p. 63-106. 
encabezados bajo el rótulo general de Sacra Amori et Dolori, y dedicados a los distintos amores terrenales de Lope, y una edición del auto de La maya, sin ningún tipo de preliminares explicativos. En suma, un más que loable esfuerzo por acercar a Lope a un público poco familiarizado con el teatro clásico.

La vocación teatral de Felipe Lluch Garín, como apunta García Ruiz se inició en las veladas que tenían lugar en las Congregaciones Marianas de los jesuitas de Madrid y se consolidó después a través de las influencias escénicas de Cipriano Rivas Cherif y especialmente con el Teatro Escuela de Arte, el más importante de los grupos fundados por Rivas, que duró solo dos temporadas (1933-1934 y 1934-1935) y del que Lluch llegó a ser una pieza fundamental. Durante la Guerra Civil, Lluch permaneció en Madrid, vinculado a actividades teatrales en el entorno de la Alianza de Intelectuales Antifascistas para la Defensa de la Cultura. Durante los meses siguientes hasta el final de la guerra, Lluch experimentó un proceso de transformación políticocultural (motivado seguramente por cierto instinto de autoconservación) que convirtió al republicano y católico que había sido en un convencido falangista, que vio en el nuevo Estado fascista la oportunidad (la única desde una perspectiva posibilista) de realizar todos sus sueños de renovación teatral en un ambicioso Instituto Dramático Nacional. Sin embargo, lo único que logró fue el cargo de director del Teatro Español de Madrid a finales de 1940, que adquirió rango de Teatro Nacional y que pasó a depender del Sindicato del Espectáculo, en competencia con el otro Teatro Nacional recién inaugurado, el María Guerrero, dependiente del Ministerio de Educación. Lluch, pese a la magra materialización de sus deseos, se lanzó con entusiasmo a revitalizar los clásicos españoles hasta su prematura muerte en junio de 1941, justo cuando había logrado situarse en condiciones de hacer mucho por la modernización de la escena española. En este contexto vital y personal, el propio Lluch dedicó al centenario de Lope cuatro artículos ${ }^{8}$ escritos en el periódico $Y a$, escritos desde la perspectiva del profesional y del lector culto que conoce a fondo el teatro áureo en su dimensión literaria y escénica, tamizados por una fina sensibilidad católica y de labor pedagógica de difusión del creador del Arte Nuevo, pero alejados sus comentarios de una manipulación política y nacionalista recalcitrante, que será, no obstante, el sello distintivo del todo el teatro clásico a partir de la década de los años cuarenta. No hay, por tanto, en los escritos de Lluch ninguna crítica o alusión relativa al ideal monárquico, al ideal católico o al ideal nacionalista, que eran las obsesiones de la derecha radical, encabezada por la Falange Española, visibles tanto en la revista Acción Española, como en Haz: semanario deportivo universitario que llevaron a cabo una auténtica manipulación de la figura de Lope durante el Tricentenario?.

7. Ver Víctor García Ruiz, Víctor, Teatro y fascismo en España: el itinerario de Felipe Lluch, Iberoamericana / Vervuert, Madrid / Frankfurt, 2010, p. 19-120.

8. Son los que siguen: «Tres comedias de Lope sobre san Isidro», 15 de mayo de 1935: s. p.; «Lope, olvidado por su patria», 10 agosto 1935, s. p.; «Sus obras renuevan la escenografía», 22 agosto 1935, s. p.; y «El teatro religioso de Lope de Vega», 30 agosto 1935, s. p.

9. Para la labor editorial de Acción Española con respecto a Lope, ver David Rodríguez-Solás, 
Se estrenó Lluch el día de san Isidro (15 de mayo) con un texto en el que comentaba tres comedias lopescas sobre el santo de Madrid: «Tres comedias de Lope sobre san Isidro». Las dos primeras tienen la extraña particularidad de constar de solo dos actos, debido a que tenían que ser representadas las dos en un mismo día, en la plaza de Palacio, durante las fiestas de la canonización del santo en 1622. Se trata de La niñez de san Isidro y La juventud de san Isidro. La tercera de las comedias, San Isidro, labrador de Madrid -cuya próxima puesta en escena en Madrid anuncia Lluch-, repite y refunde la materia de las otras dos comedias.

En «Lope, olvidado por su patria: el estado no ha cumplido su misión docente» (18 de agosto), Lluch señala con cierta amargura como: «el pueblo español, falto de apoyo y estímulo, enviciado por años de desprecio hacia todo lo sustantivamente patrio, ni ha sentido siquiera curiosidad por la obra del poeta y ha dejado desiertas las salas en las que, con más o menos acierto, pero siempre con buena voluntad, se hablaba de Lope o se representaba alguna de sus comedias». Cita luego la publicación de la revista Fénix a cargo de unos «jóvenes eruditos, celosos rebuscadores de Lope», y otras iniciativas:

esfuerzos abnegados todos; pero inútiles. Inútiles porque ha faltado el resorte capital [...] Inútiles porque ha faltado el apoyo y el esfuerzo del Estado, que se ha circunscrito a nombrar una Junta constantemente renovada y desautorizada [...]; a fijar para los Concursos de Escultura, Música y Literatura temas relacionados con Lope; a lanzar una emisión de sellos [...], y a excitar el celo de los rectores de Universidades para que alleguen fondos.

En suma, Lope seguirá siendo poco profeta en su tierra, un verdadero peregrino en su patria "mientras no se cree esa conciencia y ese deseo de cultura tradicional espańola», que debía haberse iniciado en este Tricentenario.

En el tercero de los artículos, "Sus obras renuevan la escenografía» (22 de agosto), adquiere preeminencia el director de escena sobre el fino lector. «El teatro clásico ha impuesto normas de actualidad, y ha bastado volver trescientos años atrás en la dramática española para que se advierta un paso adelante en la escenografía». Se refiere Lluch a la arquitectura escénica y a la llegada una nueva forma de organización de la escena a partir de «tonos neutros, las luces aisladas, las escaleras y plataformas, los arcos y las rampas». Para Lluch no es desde luego un posicionamiento meramente estético, de cambio de la perspectiva visual escénica, sino de algo mucho más definitivo: esa arquitectura novedosa implica una «interpretación simbólica del pensamiento del autor y una lectura radicalmente nueva del espíritu de la obra». Concretamente, se refiere Lluch a los montajes de Emilio Burgos, Manuel Fontanals y Sigfrido Burmann. Este signo de modernidad es el que aplica a continuación a los autos sacramentales. El final de este tercer artículo, y el cuarto en su conjunto (30 de agosto) «El teatro religioso de Lope de Vega», se ocupan expresamente de varias

Teatros nacionales republicanos: la Segunda República y el teatro clásico español, Iberoamericana / Vervuert, Madrid / Frankfurt, 2014, p. 194-204; y Marta García Peña, "Acción Española y el tricentenario de Lope de Vega», Anuario Lope de Vega. Texto, literatura, cultura, 21, 2015, p. 29-45. 
cuestiones que atañen a sus autos. En ambos, de forma global, lo que aflora es la preocupación por dos temas capitales. El primero guarda relación con su faceta de escenógrafo y el segundo, con la dimensión popular de Lope como reclamo para la búsqueda de un nuevo público.

Sobre el primer asunto, lo que hace Lluch es comentar la puesta en escena de los autos sacramentales que con motivo de los actos conmemorativos del Tricentenario se iban a representar en varios escenarios de la capital española. Fue la respuesta oficialista del gobierno de la CEDA (Conferederación Española de Derechas Autónomas) frente a las acusaciones de desidia que comenzaron a llover desde diferentes frentes. El objetivo de las representaciones era «establecer un íntimo contacto de las masas con el genio de nuestra raza». Para esta ocasión el Ayuntamiento de Madrid eligió tres autos sacramentales: La siega, La puente del mundo y La locura por la honra. Según relata Rodríguez-Solás ${ }^{10}$, las obras atrajeron al público madrileño, que asistió en masa a las representaciones y también pudo seguirlas en directo a través de la radio. Se cuidó el didactismo de las representaciones, que cada noche fueron presentadas por un experto, encargado de proporcionar a los asistentes una sucinta explicación sobre el texto. El encargado de los decorados fue Sigfrido Burmann, que en consonancia con lo señalado arriba, intentó llevar a cabo una recuperación arqueológica de estas representaciones huyendo «deliberadamente en su realización de todo lo que pudiera recordar el teatro». Burmann optó por "una sencilla embocadura formada por dos varales altos que [sustentaban] una cortina, y tras los cuales se [alzaban] dos columnas ochavadas con un poyete a su alrededor y unas rejas como único motivo ornamental», un escenario a propósito simple, que apuraba su dimensión simbólica con el espacio natural donde se ubicaba. Así, en pleno espíritu de recuperación y de no ruptura con el pasado, las representaciones tuvieron lugar al aire libre y en distintos enclaves relacionadas con las «viejas plazas matritenses del clásico Madrid lopesco del xvii». De esta manera, resaltaban «en el fondo, unos sencillos apliques sobre el muro viejo y patinado de iglesias y casas señoriales. El tono de tan sucinto decorado, en ocres y oro viejo, para que a un tiempo se [destacase] y se [fundiese] con el gris de las piedras centenarias que le [servían] de fondo. Y todo medido y armonizado para que dentro de su sencillez y su reducido tamaño de idea de grandiosidad y arquitectura; que nada [pareciese] pintado, sino construido».

El auto de La siega tuvo lugar en la plaza de las Comendadoras el 25 de agosto, con bastante asistencia de público que quedó arrobado ante la magnitud de la enseñanza evangélica que contenía el texto, y todo eso a pesar, como señala el crítico teatral Juan González Olmedilla, de que el público solo disfrutó "hasta donde se lo permitía el conceptismo del texto». La obrita, que relata en clave sacramental la parábola del sembrador (Mateo, 13, 24-30) -encargado de separar el grano de la cizaña-, alterna la presencia de personajes concretos con otros de carácter alegórico como el Hebraísmo, la Secta, la Idolatría y la Herejía. 
La puente del mundo, por contra, fue representado el 26 de agosto en la plaza de la Paja. El auto vierte a lo divino un pasaje inserto en la Historia del emperador Carlomagno y de los doce pares de Francia, una traducción realizada por Nicolás de Piamonte en 1521. Más en detalle, La puente del mundo dramatiza los sucesos contenidos en el segundo libro de la Historia que narra las hazañas del rey y los doce pares de Francia contra Fierabrás y Balaán. Sin embargo, Lope aprovecha una mínima parte de la historia pues sacraliza sólo la que hace mención al episodio central del puente custodiado por el gigante Leviatán ${ }^{11}$.

La última representación tuvo lugar el 30 de agosto en la fachada de la basílica de San Francisco el Grande. Se trata del auto La locura por la honra, que de nuevo es una versión a lo divino de la comedia del mismo título. Para la función se contó con «efectos de luz, acordes en todo momento con los distintos motivos simbólicos», y en este caso de nuevo la asistencia de público fue más que notable. En el texto, el Príncipe de las Tinieblas trata de seducir a dońa Blanca, casada con el Sosiego. El auto termina con la derrota del maligno seductor y la intervención final de Cristo, que provoca el arrepentimiento de doña Blanca.

El engolado remate del artículo tiene un aire que recuerda el espíritu idealista de las primeras iniciativas teatrales de la República: «Y el público madrileño, en pie, como hace trescientos años, volverá a escuchar con asombro y recogimiento, como hace trescientos ańos, los versos maravillosos, frescos y galanos del poeta nacional por excelencia».

La segunda cuestión tiene que ver con la vindicación de Lope como autor dramático popular, y al que Lluch ve alejado de complejas elaboraciones teológicas y ajeno al rígido formalismo de la retórica escolástica. Un Lope popular sí, pero que sabe con tiento aunar «la alegoría erudita con la tradición popular, la cita bíblica con el romance viejo, y la verdad eterna con el cantar en boga». Las palabras de Lluch esconden en realidad un prejuicio muy extendido que oponía la accesibilidad de los textos lopianos a la densa red de relaciones y referencias teológicas que trufan los autos de Calderón. La idea de fondo contextualiza los autos de Lope como algo accesible y conectado directamente con las expectativas de los espectadores del siglo XVII, y por ende, muy apto para su degustación por el ingenuo público de la Segunda República. «Su arte humano, popular y generoso, no podía someterse con facilidad a la rigidez de una argumentación escolástica, ni constreñirse a la aridez de una controversia para naufragar en ellas. Su fresca y fácil poesía, su rápida y fragante concepción dramática no podían sujetarse a la lenta elaboración de la alegoría ni a la fatigosa explicación del simbolismo bíblico o filosófico». Se intuye, por tanto, una diferencia con respecto a Calderón, muy alejado de una confección naturalista rural del paisaje en el que los personajes, «incluso los puramente simbólicos, visten y aun hablan como pastores o campesinos; la acción se

11. Para más detalles sobre este auto, ver Juan Manuel Escudero Baztán, «Sacralizaciones artísticas en los autos sacramentales de Lope. El caso de La puente del mundo", Revista de Literatura, 2016, en prensa. 
basa en las faenas agrícolas o los cuidados del ganado, y hasta los coloquios amorosos entre Cristo y el alma tienen dejos de idilios populares, en los que con frecuencia se intercalan canciones y villancicos». Hay una valoración positiva en la débil percepción y organización de los materiales alegóricos. Falsa a todas luces, pues el universo del auto lopiano muestra muchas veces una extremada complejidad. La falta de una columna central, que debilita la cohesión del trabado sistema de simetrías alegóricas, se sustituye en Lope por una sacralización de elementos dispersos, tomados en su mayoría del mundo pastoril. Es decir, hay un cambio en la focalización de la arquitectura dramática porque la materia pastoril no se subordina a las necesidades imperativas de la traslación sagrada, sino que impone su presencia, y determina los cauces expresivos de la «divinización» del argumento ${ }^{12}$. La sacralización lopiana, fragmentaria también, se caracteriza, desde la perspectiva del discurso formal, por una tendencia a la composición simple y a la acumulación inorgánica de referencias y alusiones eruditas. Calderón, es más consistente, al manifestar al contrario una acusada predilección por las composiciones complejas, con sistemas trabados de referencias cruzadas de temas y motivos ${ }^{13}$.

Sin embargo, la insistencia de Lluch en subrayar la faceta popular y humana de sus autos se deja ver en cada uno de los aspectos fundamentales de su poética sacramental. Y alcanza a una amplia variedad de elementos relativos a la construcción de los personajes, el sentido pictórico y cromático de su puesta en escena, la técnica dramática y en la misma elección de los temas.

La pintura de personajes incide en la presencia de realidades concretas y de conformación de un horizonte de expectativas sentimental del espectador del diecisiete. Así, "Cristo es llamado Pastor, Esposo, Labrador Celestial, Señor de la Heredad. El Alma es siempre la Esposa o la Cordera, muy pocas veces el Hombre y nunca la Naturaleza Humana». Las referencias pastoriles alcanzan incluso al Demonio cuya «intervención en los autos de Lope es muy escasa, en contraste con lo que ocurre en Calderón, que casi siempre lo utiliza como eje y expositor del conflicto dramático, se disfraza bajo los bellos nombres de Competidor o Pastor Lobo». Este ideario sentimental, aliado con la tendencia lopiana a la concreción, sufre solo esporádicos desvíos que lo acercan a Calderón -realmente estos desvíos son mucho más numerosos de los que señala Lluch-y solo en algún auto, como La siega «aparecen esos gigantes del simbolismo tan gratos a Calderón: el Hebraísmo, la Fe y la Herejía, y solo en algún otro, como en la representación moral de El viaje del alma [...] aparecen sus potencias: Memoria, Entendimiento y Voluntad, inseparables del Hombre de Calderón».

La misma concreción sentimental alcanza al sentido pictórico de Lope que se manifiesta en una puesta en escena nunca abstracta, donde funcionan escenarios

12. Ver Juan Manuel Escudero Baztán, «Sacralizaciones artísticas en los autos sacramentales de Lope. El caso de La puente del mundo", Revista de Literatura, 2016, en prensa.

13. Ver más detalles en Juan Manuel Escudero Baztán, «Estructura y alegoría en el auto sacramental La Maya de Lope de Vega», Hipogrifo. Revista de literatura y cultura del Siglo de Oro, en prensa. 
circunscritos a realidades muy concretas «adheridos a la tierra, llenos de paisaje, de luz, de color y aun de aroma y de sonidos». No hay una alegorización metafísica del espacio, una topografía imposible de toda descripción física, sino una sucesión constante de "prados y montańas, entre flores y mieses, junto a cabañas y apriscos», y de referentes visuales llenos de color y notas concretas sobre la corporeidad de los objetos que conforman esa puesta en escena: vestidos y acotaciones espectaculares potencian lo que por otro lado es un rasgo constante en todo el género sacramental y del que participan por igual tanto Lope como Calderón.

En ellas indica cómo el Alma ha de vestir de blanco cuando está en gracia y con velo negro, cuando ha caído en pecado. Cómo el Demonio ha de aparecer vestido de tela de oro, negra, bordada de llamas; el Competidor, con capa de tafetán negro forrada con velo de plata, con unas muertes sembradas por ella; Jesús, con tunicela de rosas de oro, y el Pastor Divino, con túnica blanca bordada de estrellas, cabellera nazarena y cayado en forma de cruz.

Sobre la técnica dramática, observa la ausencia de «un todo orgánico y escalonado, con categorías definidas y técnicas dramáticas y desarrollos escénicos diferentes, bien que, ligados todos por la maravillosa unidad del drama de la Redención, tema constante de los autos calderonianos» que Calderón suele rematar al final en una obvia exaltación eucarística. Lluch era un competente lector del teatro clásico español. Sus impresiones, aun superficiales en algunos aspectos, eran capaces, no obstante, de detectar efectivas diferencias entre los modos compositivos sacramentales de Lope y Calderón. Para Calderón, la exaltación de la Eucaristía es principio y motor fundamental del andamiaje dramático. Tanto en su significado de compromiso de salvación como en sus accidentes, la presencia de la Eucaristía como sacramento prioritario organiza desde el principio el plano de las letras humanas y el de las letras divinas. No es que Lope deje de incluir el esquema final de la exaltación eucarística a la conclusión de sus autos sacramentales. En realidad, de entre sus más de cuarenta autos de atribución segura, solo en quince «o no aparece la Eucaristía en el colofón final o solo hay alusiones que no hacen de ella el asunto fundamental». Sin embargo, en aquellos en los que sí aparece como acotación final, la presencia del sacramento se debe más a la pintura convencional del género (que por tradición tiende a incluir este tipo de finales), que a la presencia necesaria de un esqueleto, fundamento de la materia argumental. En este caso, tanto la ausencia del motivo sacramental, como su nula instrumentalización, explícita solo en el plano retórico, conlleva a la desintegración de la unidad estructural, que no a la variopinta tipología de los argumentos capaces de abrazar la sustancia sacramental. «Sus autos, tan pronto se basan en pasajes bíblicos o en narraciones evangélicas -El hijo pródigo y La vuelta de Egipto- como en comedias famosas o en paráfrasis de los libros santos -La puente del mundo y el auto De los Cantares-. Tan pronto son ambiciosos compendios teológicos $-E l$ heredero del cielo y El nombre de Jesús- como sencillas representaciones morales o devotas -Las aventuras del hombre y Las bodas entre el Alma y el Amor Divino. 
En suma, concluía Lluch en su artículo, los autos de Lope eran «en realidad un conjunto de bellísimas escenas líricas, rebosantes de ingenuidad y candor, de ternura y humanidad, entre las que apenas se percibe un hilo de acción que las engarce, y que solo alcanzan unidad de pensamiento y palpitación dramática cuando se fundan en ejemplos rurales o en leyendas populares glosadas a lo divino». Todo al servicio de un teatro religioso que debía actualizarse y servir a la enseñanza moral y al deleite estético del público nacido al calor de las corrientes reformistas del gobierno conservador de la Segunda República. «Bien podrían servir de ejemplo y experiencia -en un posible y necesario retorno a nuestra escena clásica y católica- para comprobar, qué es lo que aún vive en el teatro religioso de Lope y qué lo que todavía no ha muerto en el sentimiento devoto y teatral del pueblo español».

Así pues, para Lluch (y en menor medida para otras iniciativas editoriales de talante conservador como Cruz y Raya), Lope representa una ocasión de renovar el teatro español por dos vías: la libertad de una escenografía esencialista (que casa muy bien con el tono sinecdóquico del teatro del siglo XVII) que no se limite a ilustrar las obras, sino que interprete su esencia dramática; y el carácter marcadamente popular como piedra de toque para la conquista de nuevos públicos para el teatro. Su dimensión religiosa, consustancial a sus autos y comedias religiosas, forma parte de su visión del mundo y de las expectativas tocantes a su vertiente de homo historicus, y carece de tintes de propaganda política. Su optimismo en cuanto a la modernización estética que aportaban a la escena Lope y los demás clásicos se fundía plenamente con su fervorosa comunión con los ideales patrióticos y populistas de La Barraca y de las Misiones Pedagógicas. 